\title{
Consideraciones sobre la presencia de lo andaluz en el cine español (durante el franquismo)
}

\author{
Víctor Amar \\ (Departamento de Didáctica. Universidad de Cádiz-España) \\ E.mail: victor.amar@uca.es
}

\section{Resumen}

Este artículo presenta algunas reflexiones sobre el cine andaluz en tiempos del franquismo Francisco Franco (1939-1935)-. El propósito de este texto es centrar el interés sobre el cine y España en el medio siglo. El autor se plantea la posibilidad de valerse del medio cinematográfico como una valiosa herramienta de conocimiento, de ideología y cultura.

\section{Abstract}

This paper presents some reflections on the andalus cinema in time of Francisco Franco (1935-1975). The purpose of this text is to focus on the cinema and Spain. The author outlines the possibility to use this media (cinema) as tools or ideological and cultural knowledge.

Palabras clave: Cine, cultura, ideología, diversidad, reflexión crítica.

Key words: Cinema, Culture, idelogie, diversity, critical reflection.

«Yo nací -jrespetadme!- con el cine» (Rafael Alberti).

«Al cine al aire libre,

hijo, nunca has de volver, que la mar en el cinema no es la mar y la mar es»

(Rafael Alberti).

\section{¿CONTEXTUALIZAR LA DIFERENCIA? LA IMAGEN QUE SE PROYECTA}

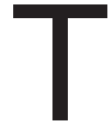

al vez, sea un graso error el simple hecho de cuestionarse la diferencia. Pero es algo que preferimos antes de caer en la indiferencia (Amar, 2003a: 51). Al igual que hiciera el profesor e investigador Luis Aranguren Gonzalo (1998) cabría "Enseñar la igualdad, aprender la diferencia". En la diferencia encontramos el verdadero patrimonio de cada uno y de la colectividad. Probablemente si no fuéramos personas diferentes seríamos, a todas luces, previsibles y homogéneos, cercanos a la seriación. Parafraseando al pensador, Ortega y Gasset, quien dijo "yo soy yo y mis circunstancias"... nosotros sutilmente incluimos la subordinada... de nuestras contradicciones y de nuestras diferencias. 
Consideraciones sobre la presencia de lo andaluz en el cine español

(durante el franquismo)

No encontramos forma de justificar la diferencia que demarca o excluye. Pero sí aceptamos la diferencia que nos hace converger en el género humano, que enriquece y nutre. Del mismo modo que no es complicado comprender que la sociedad contemporánea es el resultado de una larga ecuación de hechos y situaciones, que tiene como actuante a la diversidad, concepto que preferimos a la diferencia, ya que entendemos que el apriorismo jerárquico se diluye.

La diferencia está en la economía, en la fisura entre los que tienen y los que no tienen, entre a los que se le da la oportunidad y los que no la tendrán en su vida... entre los que la dignidad es el leitmotiv de su existencia y para los que no es así. Carlos Marx hablaba de que la riqueza de un pueblo se habría de medir no sólo por la producción, sino que igualmente por el tiempo libre que disfruta su ciudadanía, y a lo que nosotros apostillamos... quizá también por la diversidad y como las personas se incluyen en ese determinado agrupamiento social; es decir, en la capacidad de no excluir por la simple razón de ser diferente/diverso.

Los (malos) cineastas ante la incapacidad por contextualizar la diferencia la exteriorizan proyectándola en la pantalla de un cine, sin más. Los (buenos) cineastas se expresan con el imago en movimiento y enuncian o denuncian la diferencia tal como se la cuestionara Antonio Gramsci, es decir, cómo un gesto revolucionario. El arte del cine, también industria del entretenimiento y de la ideologización, cuenta en su haber con la magnitud de producir el arte por el arte pero, además, posee una faceta reivindicativa y rupturista.

En efecto, lo que caracteriza por encima de todo a la cultura de masas es que se trata de una comunicación unilateral, que funciona únicamente en un solo sentido. Los poderosos, los que controlan económica e ideológicamente la sociedad, dictaminan cuál ha de ser el contenido y el carácter de los productos culturales y de entretenimiento que se suministran a las grandes masas. (Linares, 1976: 8-9).

El cine no puede ser un mero observador, un vouyer que merodea las subvenciones y agrada, en exclusiva, a los dirigentes. Ha de posicionarse y contribuir a la construcción de personas responsables que sepan discernir y que acepten la diferencia/diversidad como algo natural y no como un handicap.

La redefinición de cultura y de la diversidad cultural, también pasaría por este propósito de asumir la contemporaneidad en su justa medida. Esta cultura contemporánea postmoderna -al menos a la que pertenece el contexto español- pasa por ser el resultado del binomio formado por la dualidad entre lo global y lo local, teniendo como consecuencia el emergente concepto glocal (Aparici, 2000). Este concepto postmoderno se asienta sobre la galopante globalización económica e ideológica, así como en sus conexiones a gran escala, contrapunteadas por la inmediatez de la exaltación de los valores -regionales, en este caso la andaluzay sentimientos específicos o las identidades localistas basadas en la historia y en el factor cultural. 
La diversidad no es igual a desigualdad. La jerarquía cultural puede llegar a impedir ver la diversidad como algo enriquecedor y natural. El encuentro entre las culturas, la convivencia entre las personas, es un acontecimiento estructural y no un hecho, meramente, excepcional. Y lo peor de todo ello es que, probablemente, terminamos asensibilizándonos ante los demás y desconsiderando lo que no nos incumbe (Colom González, 2001).

En la vida cotidiana, y en el cine, debería haber cabida para todos y todas; a la postre, lo que se pretende es aceptar y desarrollar una sociedad plural, más justa y democrática, donde a las personas se las valoren no sólo o exclusivamente por lo que hacen sino, también, por cómo lo hacen -proyectándose en la pantalla-. Estamos elaborando una simple defensa a la coexistencia, a la convivencia sin distinción o cuestionamiento alguno de etnia o color de la piel, lugar de nacimiento o supuesta capacidad intelectual, religión o estatus socio-económico, edad o ideología, condición física o mental, sexo u opción sexual...

La fuerza de cada país y del conjunto de los países de la tierra es abrir espacios múltiples que posibiliten la creación, la diversidad, las libertades. Oponerse significa empobrecerse y por lo tanto retrasar la construcción del nuevo mundo. Esta construcción necesita apoyarse en ejes culturales y los países han aprendido por dolorosa experiencia, que el respeto a las culturas ha sido su fuerza y la intolerancia la debilidad que les ha conducido al desastre (Gelpi, 1993: 28).

A todas luces, en la redacción de estas líneas introductorias lo que pretendemos es hacer un llamamiento al respeto entre los unos y los otros; como un hecho de lucidez y madurez por la convivencia personal y social... Donde el cine tiene mucho que aportar pues seduce y cautiva, además de que genera opinión y extiende un discurso. Pero al igual que se nos ha enseñado a leer y escribir habría que hacer lo mismo con el lenguaje del cinematógrafo, máxime cuando vivimos en una sociedad eminentemente audiovisual (Amar, 2000).

El cine no puede ser un útil exclusivo para el divertimento sino que, además, ha de llegar a ser una herramienta para la enseñaza-aprendizaje, una puerta abierta para considerar y aceptar la diversidad. Aunque en ocasiones ha sido un recurso para alienar, crear y perpetuar estereotipos que poco, o nada, han aportado a la visión de un pueblo fuera de su ámbito. Por ejemplo, la visión que el cine franquista dio sobre los hombres y las mujeres de Andalucía; dentro y fuera de las fronteras de España. Con ello, la asimilación de la imagen del otro nos la planteamos a partir de la nuestra. Con ello, reflexionamos sobre la visión de lo andaluz durante el franquismo y como todavía ésta se perpetúa, así como nos detenemos para focalizar intentos que pretenden quebrar la presencia de ciertos estereotipos anclados en el pasado. 


\section{ANDALUCÍA EN EL CINE FRANQUISTA.}

Ciertamente, la visión de Andalucía ha cambiado con respecto a la mirada que proyectaba, en la gran pantalla, el pasado régimen franquista. La herencia de la pandereta y folclóricas, además de los señoritos y juergas se han diluido notablemente. Sin embargo, todavía quedan resquicios que conforman parte del imaginario falaz, fruto de intereses por difundir esos arquetipos (aunque son casos aislados y, afortunadamente, sin mayor trascendencia).

La imagen compartida por el pasado régimen fascista acostumbraba a presentar a los andaluces y a las andaluzas bajo unos estereotipos 'estupidizantes' y groseros. Ellos podrían ser caciques del sur, sin pudor y explotando a los campesinos. Ellas podrían ser mostradas en la pantalla como empleadas del hogar, abnegadas y sujetas a la tradición que las perpetuaba en su rol de mujer, madre y esposa. O bien, en términos generales, el cine andaluz quedaba constreñido a previsibles géneros cercanos al melodrama o a cándidos sketches pseudocómicos.

Se crea un género cinematográfico que nunca llegó a dar un film de calidad: la andaluzada. (...) determinada visión de Andalucía se convierte en símbolo de España toda.

Es la Andalucía de pandereta y castañuela, del baile y del cante, del señorito calavera y bonachón y el bracero respetuoso, alegre y resignado, de la señora distante pero caritativa y la joven humilde pero encantadora. También la Andalucía divertida y religiosa, locuaz y sensitiva. La Andalucía que es modelo de un mundo que se supone bien y cristianamente hecho. Esta Andalucía es la que se quiere para toda España y ésta será la imagen exportable (Urrutia, 1984: 28).

En este sentido, estamos ante una tipología cinematográfica que se ha conformado a partir de estereotipos en la pantalla. En muy pocas ocasiones, se habla con propiedad de un cine andaluz de inspiración en la grandeza y en la problemática de esta parte meridional de la península ibérica. Un modelo de cine andaluz en el franquismo tenía su extensión en Madrid y Barcelona, donde los emigrantes llegaban a trabajar en las productivas urbes del centro y de Cataluña... y, en ocasiones, se retrataba el subdesarrollo de Andalucía a través de españoladas o subproductos de la época.

Por otro lado, el camino más corto para los realizadores andaluces pasaba por estas dos ciudades españolas que, de una u otra forma, fagocitaban la sensibilidad y terminaban por hacer lo que únicamente se podía hacer: cumplir con el régimen dictatorial o, para transgredirlo, ampararse en la literatura o en la historia. En este sentido, los órganos censores se hacían más permeables a las palabras e ideas expuestas por esos personajes procedentes de las letras o la tradición. Grosso modo, el cine se mostraba temeroso, engañoso y estaba sometido a los intereses del dictador (que terminó imponiendo el gusto de aquella etapa de la historia de España). 
Igualmente, el cine durante la dictadura franquista fue mucho más que sentarse frente a él en una sala de proyecciones. Era asomarse a la ventana de la libertad, de la imaginación... cuando la realidad estaba prohibida. Sin duda, el cine ocupaba el espacio del imaginario que ayudaba a liberarse de la frustración e invitaba a evadirse de las carencias y la falta de esperanza. Mientras, a los dictadores (pues nos referimos a aquellos que suscribieron el proyecto franquista) les preocupaba el no poder controlar aquellas miradas y mentes, ya que este patrimonio del ser humano es difícilmente controlable pero, en ocasiones, llegó a ser manejado -y no sólo en Andalucía durante este período sino en la mayoría de los países y en diferentes momentos de la historia-.

Recordemos que el cine jugó un papel importante en el día a día de los españoles de la posguerra. Era casi un ritual social y de seducción, donde cabía la posibilidad de sentirse identificado con el protagonista e, igualmente, romper con la monotonía, la escasez de libertad de alimentos... No obstante, ¿quién podría controlar la imaginación del espectador? (Amar, 1995: 290-291).

El cine andaluz, si es que existió, o si existió se encargaron de que no se reconociera como tal, es un claro ejemplo de anulación. Se encargaron de que el conocimiento y la comprensión de la cultura andaluza brillara por su ausencia y la asimilación fuera una imposición sin apenas estima por los otros. ¿Qué intereses hubo para ello? No se podría argumentar que fueran sólo de índole económica; se barajarían otros de naturaleza ideológica y de (no; negación de la) identidad.

El cine andaluz en estos años, por un lado, contó con la herencia del teatro de los hermanos Quintero y el tipismo, el universo del señorío y el torero, las venganzas a navajazos... Y, por el otro, las temáticas genuinamente andaluzas como serían el mito de Carmen, el bandolerismo y el flamenco, entre otras; además del subdesarrollo y la migración, que tuvieron un desarrollo sesgado. Pero, igualmente, el cine andaluz contó con la realización de documentales y una importante política festivalera, así como con el quehacer de los cineclubs que invadieron el panorama andaluz en el tardo franquismo... incentivando el cambio. Estos fueron algunos de los ingredientes del séptimo arte en Andalucía perpetuando y, a la vez, pretendiendo romper esa imagen obsoleta y engañosa con andaluces 'vagos' y andaluzas 'bailaoras'. No obstante, jóvenes cineastas, actores-actrices y público en general clamaban un cambio en la mentalidad del cine periférico del sur, servil y banal al servicio de los intereses hegemónicos, capaz de reírse de lo andaluz, en vez de reírse con los andaluces.

El cine español ha tratado el género andaluz de forma indigna. Por supuesto que no se ha querido profundizar en unas circunstancias históricas, culturales, económicas, políticas... pero tampoco se ha sabido respetar una mínima altura estética dentro de las convenciones (Aguilar, 1980: 43). 
La asimilación de la imagen del otro en el cine andaluz fue fruto de los intereses de la producción, distribución y exhibición. La cultura andaluza se desgastaba en la pantalla que veía como no se evolucionaba y la andaluzada eclipsaba a las múltiples posibilidades que se podrían generar. Por ejemplo, a partir de los textos de Federico García Lorca, inspirándose en la vida de un anarquista del siglo XIX, llamado Fermín Salvochea... o bien el cine fruto del ímpetu de la imaginación de los jóvenes guionistas del sur de España.

Todo aquellos años forman parte del bagaje cultura de los andaluces y andaluzas que sabían de los muchos intereses que reinaban sobre el cine. Un entretenimiento, un arte... O una industria del entretenimiento que en ocasiones permitía brotar el arte y la belleza, la sinceridad y la realidad... Tiempos de la normalización lingüística que hizo del habla andaluza un reducto en la pantalla para sumisas empleadas del hogar, graciosos porteros de inmuebles o para delincuentes de poca monta. Años que perviven en el imaginario de los demás; un recurso que tristemente aún se recurre y en cine o televisión el andalucismo es sinónimo de burla o mero tipismo con sabor rancio y pretérito.

\section{POR UN DEBATE SOBRE LA IMAGEN CINEMATOGRÁFICA DE ANDALUCÍA}

La idea de estas líneas ha sido iniciar el debate en torno a una secuencia de la presencia de lo andaluz en el cine español (durante el franquismo) en años donde imperaba la sensibilidad de Luis García Berlanga, la reivindicación de la Escuela de Barcelona y las pretensiones de la revista Nuestro Cine, además de la necesidad de apertura del nuevo cine español, así como el primer cine del sevillano Manuel Summer... o la lucidez de Juan Antonio Bardem quien en las Conversaciones de Salamanca, en el medio siglo español, apuntó que "El cine español, al cabo de sesenta años, es políticamente ineficaz, socialmente falso, intelectualmente ínfimo, estéticamente nulo e industrialmente raquítico" (Sadoul, 1977: 29).

Lejos de caer en la presunción de creer estar en la posición de la verdad, nuestro discurso se ha intentando desenvolver alrededor de la duda, ya que como señalaba el matemático francés del siglo XVII, Blaise Pascal, aquel que duda y no investiga se torna no sólo infeliz, sino también injusto. E, igualmente, hemos podido dar la impresión de estar invadidos por el pesimismo, interpretado como resentimiento; sin embargo, hemos querido ser realistas, interpretándolo como revisionista de unos años de cine y franquismo en Andalucía.

El debate sobre la imagen que se proyecta, proyectaban y proyectaremos es una reflexión en voz alta sobre la ilusión de saber, que alimentamos llevados de la megalomanía de conocer, sin más, contrapunteando el hecho de obviar lo más inmediato: la imagen del otro y la de nosotros mismos. 
El mal que nos aflige es quizás el peor de cuantos conocimos hasta ahora: la semicultura, con la cual todos los medios de comunicación nos bombardean ahora a todos nosotros.

La semicultura es peor que la ignorancia, porque nos engaña. Su engaño hace posible tenernos atados de pies y manos, subyagados por quimeras.

La semicultura, en efecto, es la ilusión de saber (Rossellini, 1979: 113).

No cabe la menor duda que el cine andaluz es mucho más que el sesgo presentado por la manipulación franquista. Temáticas del cine andaluz han sido motivo de inspiración para cintas de la autoría de C.B. de Mille, Charles Chaplin, Ernest Lubistch, Otto Preminger o bien Jean-Luc Godard, entre otros tantos directores de trayectoria y proyección internacional.

Sin embargo, lo preocupante es cómo nos ven los del otro lado, los de cualquier otro lado. Cuánto pesa el pasado de la imagen cinematográfica con respecto a la visión que tienen los otros de nosotros. Cuál es la imagen que proyectamos... Además de cómo nos vemos nosotros mismos.

Nuestra opción ha sido dejar abierto el debate para construirlo con el lector/ espectador y advertir, tal como decía San Agustín que... en lo necesario, unidad; en la duda, libertad; y en todo, comprensión. Suscribimos lo de comprensión, pues es la vía para asimilar la imagen del otro sin querer modelarla a nuestros intereses, de desear modificarla de acuerdo a nuestros caprichos. La comprensión, a nuestro entender, es la base del respeto y del progreso entre los seres humanos... Sin olvidar que el cine, posiblemente, es una fábrica de sueños y de mentiras.

Es muy probable que la imagen que proyectaremos sobre los demás a partir del cine sea la que otros (los que nos dirigen) hayan querido mostrar. El cine es un arma peligrosa si no se controla, pues la mirada y el imaginario se nutren de él, además de ser ambos aspectos apuntados -la mirada y el imaginario- dos órganos en continua construcción.

La imagen equívoca, quizá porque interesa se extiende a través del cine, pero la verdadera imagen también nos llega gracias al cine. Con ello, quien controla el cine controla la imagen de unos y de los otros y, en este sentido, la liberación llega a través de la cultura y la educación en cine.

(...); analizar en el film tanto la intriga, el decorado, la planificación, como las relaciones del film con lo que no es el film: la producción, el público, la crítica, el sistema político. De este modo podemos esperar comprender no sólo la obra, sino también la realidad que representa (Ferro, 1995:39).

Tal como dijo Carlos Marx, la ignorancia jamás fue útil a nadie, así que hay que ver cine, el de los unos y el de los otros. Es la única manera de finalizar con lo que el cineasta español, Fernando Fernán Gómez, indicó como "la colonización 
del gusto" (1995: 49-50). Y aceptar, tal como expresara el pedagogo Paulo Freire (2001), la importancia que tiene la conciencia crítica -también para el espectadorpues con ella será capaz de transformar esa realidad mediada y mal intencionada.

\section{ANDALUCES Y ANDALUZAS. PARA CONTINUAR EL DEBATE}

El cine se muestra como una importante ventana al exterior que nos permite asomarnos a otras realidades. Es cierto que el séptimo arte posee la intención de fabular y el espectador de cine ha de desarrollar la capacidad de disfrutar y aprender ante un film. Con la intención de incentivar en el presente artículo el debate sobre los andaluces y andaluzas en el cine en tiempos del franquismo hemos eludido la presencia de títulos o directores/actores, aunque lógicamente hemos colocado algunos de estos. La idea que se ha perseguido ha sido la de activar la mirada y la sensibilidad sobre el tema que nos ocupa... con la intención de compartir.

Las dictaduras políticas tienen una preocupante extensión en el control en la mirada y, por consiguiente, en la producción cinematográfica. Tal vez, tenga mucha razón el cineasta barcelonés Néstor Almendros cuando decía que a los dictadores les gusta el cine. Suponemos que les gusta como espectadores pero, también, y ahí radica nuestra preocupación para controlar el sentir de los demás, mantener bajo su dominio la mirada y las posibilidades de imaginar, de comparar, de constatar y contrastar.

Estas líneas han sido redactadas a modo de reflexión planteando unas consideraciones sobre la presencia de lo andaluz en el cine español (durante el franquismo). Un pretexto para detenernos a pensar sobre el cine y la dictadura franquista pero teniendo como denominador común lo andaluz. Unas personas que han dado la imagen de subdesarrollados socialmente y subnutridos intelectualmente; sin embargo, en la actualidad el discurso es todo lo contrario... Estamos ante una comunidad que reivindica su parcela patrimonial y su reconocimiento en la gran pantalla... ya que:

Probablemente, el cine en Andalucía se podría reducir al que se producía durante los años del franquismo y que, en la actualidad, tiene un rancio sabor pretérito (Amar, 2003b: 111).

Unas consideraciones para iniciar un arduo y veraz análisis sobre el cine andaluz en el contexto español en las décadas de la dictadura franquista. Unas reflexiones -de ayer a hoy-que han pretendido esclarecer una parcela de la validez y la calidad del cine en el sur de la península ibérica. Una invitación repleta de convicción para aportar un poco de luz a que el cine andaluz durante el franquismo fue plural aunque, en ocasiones, ha perdurado la intención de la mirada homogénea.

Con todo ello, el presente artículo, que hemos determinado en titular de modo genérico "Consideraciones sobre la presencia de lo andaluz en el cine español 
(durante el franquismo)", se ha estructurado en cuatro secuencias abiertas a la mirada del lector/espectador para su disfrute y reflexión.

\section{REFERENCIAS BIBLIOGRÁFICAS:}

AGUILAR, J.C. (1980): "Cine andaluz: género e industria", en UTRERA, R. y DELGADO, J-F. Cine en Andalucía. Utrera, Argantonio Ediciones Andaluzas; 42-46.

AMAR ,V. (1995): "Literatura y cine español en el medio siglo: introducción a un posible a un posible catálogo", en RAMOS ORTEGA, M. J. y PÉREZ-BUSTAMENTE MOURIER, A. (Eds.): Literatura española alrededor de 1950: panorama de una diversidad. Cuadernos Drago, 2. Cádiz; 286-310.

AMAR, V. (2000): "La alfabetización audiovisual a través de la educación con el cine", en Comunicar, 15; 141-149.

AMAR, V. (2003a): "Interculturalidad y nuevas tecnologías", en HERRERA CLAVERO, F. et alli. (Coords.): Inmigración, interculturalidad y convivencia. Ceuta, Instituto de Estudios Ceutíes; 49-62.

AMAR, V. (2003b): "El cine en Andalucía: más de cien años de convivencia", en AMAR, V.: Comprender y disfrutar el cine: la gran pantalla como recurso educativo. Huelva, Comunicar; 111-122.

APARICI, R. (2000): "Trece mitos sobre las nuevas tecnologías de la información y de la comunicación", en Kikiriki, 58; 38-42.

ARANGUREN GONZALO, L. (1998): De la tolerancia a la interculturalidad: un proceso educativo en torno a la diferencia. Madrid, Anaya.

COLOM GONZÁLEZ (2001): El espejo, el mosaico y el crisol. Modelos políticos para el multiculturalismo. Barcelona, Anthropos.

FERNÁN GÓMEZ, F. (1995): Desde la última fila. Cien años de cine. Madrid, EspasaCalpe.

FERRO, M. (1995): Historia contemporánea y cine. Barcelona, Ariel.

FREIRE, P. (2001): Pedagogía de la indignación. Madrid, Morata.

GELPI, E. (1993): "Pedagogía intercultural y problemas socio-educativos de las minorías", en VV.AA. Educación multicultural e intercultural. Granada, Impredisur; 25-34.

LINARES, A. (1976): El cine militante. Madrid, Castellote.

ROSSELLINI, R. (1979): Un espíritu libre no debe aprender como esclavo: Escritos sobre cine y educación. Barcelona, Gustavo Gili.

SADOUL, G. (1977): Diccionario del cine: cineastas. Madrid, Istmo.

URRUTIA, J. (1984): Imago Litterae: cine, literatura. Sevilla, Alfar. 